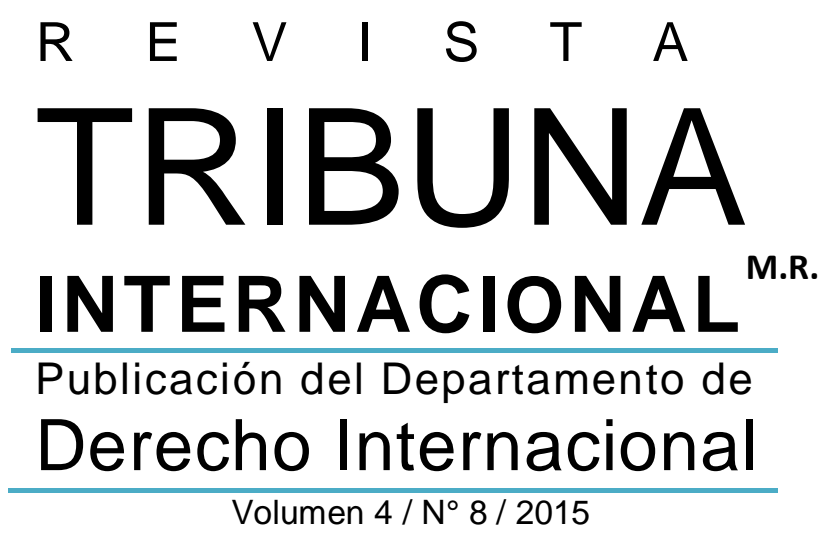

FACULTAD DE DERECHO 


\section{Rector de la Universidad de Chile}

Ennio Vivaldi Véjar

Av. Alameda Libertador Bernardo O'Higgins

1058, Santiago

\section{Representante legal}

Davor Harasic Yaksic

Decano de la Facultad de Derecho

Universidad de Chile

\section{Director Departamento Derecho}

Internacional

Edmundo Vargas Carreño

\section{Director (S) Revista Tribuna Internacional}

Mario Arnello Romo

\section{Editor General Revista Tribuna Internacional}

Luis Valentín Ferrada Walker

\section{Comité Editorial}

Íñigo Álvarez Gálvez (Universidad de Chile, Chile)

Gonzalo Aguilar (Universidad de Talca, Cbile)

José Carlos Fernández Rosas (Universidad

Complutense de Madrid, España)

Claudio Grossman (American University, EE.UU.)

Mattias Kumm (New York University, EE.UU.)

Hugo Llanos (Universidad Central, Chile)

Cecilia Medina (Universidad Diego Portales, Chile)

Elina Mereminskaya (Universidad de Chile, Chile)

Mónica Pinto (Universidad de Buenos Aires, Argentina)

\section{Fundador de la Revista Tribuna Internacional}

Mario Ramírez Necochea $†$

\section{Revista Tribuna Internacional M.R.}

Publicación del Departamento de Derecho Internacional de la Facultad de Derecho de la Universidad de Chile. Su objetivo es fomentar la reflexión, el debate, el análisis y la comunicación sobre el derecho internacional en forma pluralista y con rigor científico. Se publica cada semestre en los meses de junio y diciembre mediante convocatoria abierta a la publicación de artículos y monografías inéditos, comentarios de jurisprudencia, recensiones y comentarios de libros, en los campos de derecho internacional público y privado, derecho internacional de los derechos humanos y relaciones internacionales, tanto en castellano como inglés.

La Revista Tribuna Internacional fue creada por Decreto Exento No 8.466 de la Rectoría de la Universidad de Chile, de 22 de marzo del 2011.

Volumen 4/ No 8 / 2015

www.tribunainternacional.uchile.cl ISSN 0719-482X (versión en línea)

Departamento de Derecho Internacional Facultad de Derecho Universidad de Chile Av. Santa María 076, $4^{\circ}$ piso

Providencia, Santiago de Chile

\section{Diseño y producción:}

Facultad de Derecho

Universidad de Chile

Se autoriza la reproducción total o parcial del contenido de la publicación, siempre que se reconozca y cite el/ la/ los/ las autor/a/es/as y la publicación, no se realicen modificaciones a la obra y no se la utilice para fines comerciales. 


\title{
Chile-Bolivia: Un caso de diplomacia secuestrada
}

\author{
Chile-Bolivia: A kidnapped diplomacy case
}

\section{José Rodríguez Elizondo}

jarelizondo@yahoo.com

Profesor Titular Facultad de Derecho de la Universidad de Chile y Director del Programa de Relaciones Internacionales de dicha casa de estudios.

Resumen: Las demandas sucesivas contra Chile de Perú y Bolivia configuran un conflicto de poder. Por ello, el componente jurídico debe formar parte de una estrategia integral más amplia, cosa que en Chile no ha ocurrido. Para el autor, la conceptualización de los tratados como santos o intangibles, que maneja la diplomacia chilena, es de índole más idealista que realista. La realidad indica que Bolivia y Perú han tenido la voluntad de "tangibilizarlos" y eso implica la necesidad de enfrentar una realidad política y diplomática, que no soslaye la negociación.

Palabras claves: Bolivia c. Chile - Derecho Internacional - Diplomacia - Estrategia

Abstract: Successive Perwian and Bolivian lawsuits against Chile create a power conflict. Therefore, legal aspects are only a part of a wider and comprehensive strategy, although in Chile has not been understood on that manner. It is argued that consider international treaties like sacred and intangible, as Cbilean diplomacy does, it is more an idealist concept than a realist one. The reality shows that Bolivia and Peru have had the will of "making them tangible". This situation forces to confront a political and diplomatist's challenge, considering negotiation.

Keywords: Bolivia v. Chile - International Law - Diplomacy - Strategy. 


\section{Pleitos encadenados}

Fallada la demanda peruana ante la Corte Internacional de Justicia (CIJ) y en vísperas de presentarse la demanda boliviana, asistí a uno de los tantos encuentros de "expertos" realizados durante los últimos siete años. Visto que incluso destacados juristas bolivianos reconocían la precariedad técnica de esa segunda judicialización, pensé que discutiríamos el nuevo caso de manera realista. Por ejemplo, sobre cómo enfrentar política, diplomática y comunicacionalmente ese empeño artificioso del Presidente Evo Morales, asumiendo la mala experiencia con la CIJ, desmontando la ficción del bilateralismo y resistiendo la inercia del juridicismo.

Sin embargo, el debate se centró en la necesidad de estudiar a fondo la posibilidad judicial de los "derechos expectaticios" bolivianos o su versión más sofisticada de los "actos unilaterales que comprometen al Estado". Al parecer, la mayoría de los abogados internacionalistas vinculados a la Cancillería ya estaba investigando el tema. Además, habían interpretado benévolamente el fallo en el caso con Perú -la CIJ habría acogido las tesis jurídicas chilenas- y consideraban que, gracias a ese pleito, Chile había ganado una gran experiencia en litigios internacionales. La clara señal era que debíamos enfrentar el nuevo juicio, sin discutir previamente la competencia de la Corte.

Comprendí, entonces, cuatro cosas desalentadoras: Una, que volveríamos a enfrentar un conflicto de poder en el cual no habría nada que ganar. Otra, que Chile carecía de un protocolo de comportamiento político para esos conflictos. Tercera, que contratar abogados litigantes extranjeros era un recurso de doble filo. Última, que teníamos un problema no resuelto entre el derecho y la diplomacia.

\section{El paradigma actual}

Durante mucho tiempo, se estimó que la diplomacia tenía como referente único el derecho internacional, siendo éste el epítome de los usos, costumbres y protocolos de las relaciones extramuros. En paralelo, se asumía que los conflictos internacionales limitaban con las funciones primarias de la defensa nacional. Maquiavelo, a sabiendas de que no había juez internacional con imperio para ejecutar sentencias, ya había enseñado a los príncipes que el régimen de los ejércitos es "la ciencia verdadera del gobernante".

Esto generaba dos grandes percepciones en las burocracias diplomáticas: una, que la abogacía era un requisito sine qua non para el oficio y la otra, que su estatus descansaba en la 
Revista Tribuna Internacional

Volumen $4 \cdot \mathrm{N}^{\text {o }} 8 \cdot 2015 \cdot$ pp. 87-105

ISSN 0719-482X (versión en línea)

homologación con los oficiales militares. Los embajadores también eran agentes públicos jerarquizados y disciplinados, al servicio del país y por sobre los gobiernos de turno. Además, gracias a la comprensión e influencia de las grandes potencias imperiales, usaban uniformes con espada, entorchados, condecoraciones y bicornio.

A través de los siglos, aquello cambió, cualitativamente, en los "países centrales" y en las diplomacias de vanguardia de los "países periféricos". La asimetría maquiaveliana, el cordón umbilical jurídico y la simbólica homologación castrense dejaron de ser lo que eran. Hoy parece claro que el multilateralismo, el poder nuclear con su "equilibrio del terror", las sanciones que puede aplicar la ONU a los Estados -miembros o no- que considere amenazantes o agresores, el fin de la Guerra Fría, la crisis de las ideologías cosmogónicas, la globalización con sus redes transversales y las nuevas tecnologías de la información, desconfiguraron instalaciones que antes lucían como partes esenciales de la diplomacia.

En su reemplazo se ha perfilado un nuevo paradigma. Éste supone, en cuanto a dotación, lo que Sir Harold Nicolson definiera como "cuerpo permanente de negociadores profesionales"1. Así, sin mengua de la importancia de la ciencia del derecho como conquista cultural de la humanidad, las cancillerías modernas han soltado sus amarras legales para poder negociar con libertad. Se sabe, allí, que el derecho refleja una "historia congelada" y que el pacta sunt servanda no impide consensuar modificaciones de los tratados, en aras del interés nacional. Los abogados, en sus organigramas, existen como técnicos de apoyo y no como agentes conductores.

Para los diplomáticos aquello significó transitar desde la simplicidad de las soluciones jurídicas a la complejidad de las soluciones negociadas, asumiendo valores que antes sólo se exigían a los estadistas: imaginación prospectiva, creatividad, capacidad de análisis político, conocimiento de la historia (propia y de "el otro"), flexibilidad inteligente, interdisciplinariedad académica y decisión para asumir los riesgos necesarios. Esto los obligaba a asimilar los rudimentos de la estrategia, dado que ya no existía una muralla china entre la política exterior y la previsión de escenarios hipotéticos.

Por lo mismo, los reclutadores modernos hoy se orientan hacia los profesionales "afines" de talante versátil, capaces de sintetizar las capacidades de muchos expertos. Entre ellos, juristas (nivel superior al de los abogados), politólogos, estrategos, geopolíticos, economistas, historiadores, comunicadores, gestores culturales y promotores de exportación. Mediante esa "canasta" ampliada de destrezas tratan de asegurarse una capacidad de investigación multidisciplinaria, pues saben que los temas políticos que se negocian tienen historias complicadas y pueden estirarse hasta el larguísimo plazo.

Nicolson, Harold. La diplomacia. México, D.F., Fondo de Cultura Económica, 2010, p. 182.

Friedrich, C.J. La filosofía del derecho. México, D.F., Fondo de Cultura Económica, 1964, p. 331. 
En la cátedra ilustro esta evolución mediante la dinámica de "las tres D”. Esto significa que los Estados modernos hoy comienzan expresando sus objetivos en pugna mediante alegatos de Derecho; si no hay consenso -que es lo usual-, pasan a la negociación en el marco de la Diplomacia y, en caso de subsistir diferencias irreductibles, pueden acudir a la disuasión de la Defensa. Como puede observarse, en esta dinámica la norma jurídica es un referente necesario, pero no un condicionante sine qua non.

\section{Citas escogidas}

El proceso hacia el nuevo paradigma estuvo pavimentado por tesis y opiniones de autoridades destacadas. Para efectos didácticos, es bueno consignar algunas de las más representativas.

Maquiavelo, en El Príncipe, quitó piso a los letrados partidarios de la inactividad o de la reactividad: "los peligros deben conjurarse antes de que aumenten [pues] las guerras no se evitan aplazándolas”. Su diplomacia descansaba en la iniciativa política musculada.

El Cardenal Richelieu, en su Testamento Político, dijo casi lo mismo, pero de manera irónica: "En cuestiones de Estado, el que tiene el poder a menudo tiene el derecho y el que es débil difícilmente puede no estar en el error".

En tiempos de Luis XIV, el hoy clásico Francois de Calliéres (1645-1717) advirtió que los malos consejeros eran hechura del ethos juridico del personal: "la formación de un abogado inculca hábitos y disposiciones intelectuales que no son favorables en la práctica de la diplomacia". Añadió que ésta "es una profesión que merece la misma preparación y atención que los hombres dan a otras profesiones conocidas"3.

En el siglo XX, el embajador, académico y jurista francés Jules Cambon (1845-1935) puso en guardia contra "la ilusión de creer que no existen más derechos para las naciones que aquellos que los tratados les confieren". Lo explicó didácticamente en un libro de 1926, diciendo que “toda acción diplomática acaba en una negociación” y que el carácter diplomático difiere del jurídico, pues "la aplicación de las leyes y su interpretación llevan consigo en teoría un cierto rigor, que se acomoda mal con el empirismo de la política"4.

Henry Kissinger, uno de los innovadores contemporáneos más audaces (al margen del juicio ético que merezca su trayectoria política), cuenta que los grandes cambios que impulsó como

3 CALLIÉRES, Francois de. On the manner of negociating with princes. Notre Dame (Estados Unidos), University of Notre Dame Press, 1963 , p. 55.

4 Cambon,Jules. Le diplomate. París, Editorial Hachette, 1926. Se ha tenido a la vista la versión hecha en Madrid, Ediciones Españolas Hachette, 1928, pp. 23-25. 
Secretario de Estado de los Estados Unidos chocaron contra "las tradiciones legalistas" del establishment ${ }^{5}$.

Y dejo para el final una cita sorprendente del embajador peruano Juan Miguel Bákula. Como estratego de su equipo en la demanda contra Chile, impuso la tesis de que el conflicto era “estrictamente jurídico”... y así terminó asumiéndolo nuestro gobierno. Pero, en cuanto historiador y pensador de la diplomacia, Bákula sostenía en su obra mayor que judicializar era una mala manera de enfrentar los conflictos: "El tratamiento de las cuestiones de límites, enfocado como una confrontación litigiosa, casi siempre de títulos y bajo el privilegio de estrictos dogmas jurídicos - con frecuencia de elaboración doméstica- ha sido la vía más segura para desembocar en un conflicto interminable" ${ }^{\circ}$.

\section{Retraso de Chile}

El nuevo paradigma tiene como soporte una "zona gris", configurada por lo que el historiador militar británico Basil H. Liddell Hart bautizara, en 1941, como "estrategia de aproximación indirecta” y lo que el contemporáneo politólogo de Harvard, Joseph S. Nye, denomina "poder suave".

Esa zona refleja una ecuación entre el poder que emana de la letalidad de las armas y el que se proyecta desde el prestigio de las naciones. Como tal, es producto del crecimiento exponencial de actores marginales a las cancillerías y del temor al potencial apocalíptico del arma nuclear. "Al llevar la destructividad al extremo del suicidio, el poder atómico está estimulando y acelerando la vuelta a los métodos indirectos, que son la esencia de la estrategia”, escribió Liddell Hart ${ }^{7}$. Y de la diplomacia, cabría complementar.

Una síntesis didáctica sobre la interpenetración de esas percepciones fue expuesta por el abogado y politólogo chileno Luciano Tomassini, cuando señaló que "la diplomacia ha oscilado siempre entre el derecho y el uso de la fuerza, con una instancia intermedia que es la negociación". En esa línea, concluía que la negociación es "el método normal, más satisfactorio

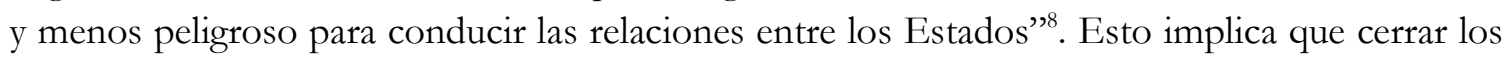
espacios para la solución negociada y oportuna de las controversias graves, invocando el

Kissinger, Henry. La Diplomacia. México, D.F., Fondo de Cultura Económica, 1995, p. 735.

6 Vid. BÁkula, Juan Miguel. Perú entre la realidad y la utopía. 180 años de política exterior. Lima, Fondo de Cultura Económica del Perú, 2000, t. II, p. 1157. ¿Es necesario ilustrar este tema recordando que el fallo de la CIJ, en el caso Chile-Perú, dejó vigente la controversia por el "triángulo terrestre"?

7 Vid. Liddell Hart, Basil H. Estrategia: La aproximación indirecta. Madrid, Ministerio de Defensa de España, 1989, p. 19.

8 Tomassini, Luciano. Teoría y práctica de la Política Internacional. Santiago, Ediciones de la Universidad Católica de Chile, 1989, pp. 247 y 253. 
derecho, abre dos puertas de acceso complicado: la del retorno a la supuestamente más expedita manu militari y la de la intervención de la CIJ, que es una muy discutible alternativa latinoamericana, en cuanto riesgosa para las diplomacias que no manejan la estrategia.

La mala noticia para Chile es que nuestra burocracia pública no se identifica con esos planteamientos. A favor del secretismo permanente -que identifica con la cautela- y a contramarcha de la modernización, suele refugiarse en "el estricto derecho", ahorrarse la imaginación y no explicar nada a la ciudadanía. Su talante confirma las viejas tesis de Max Weber, según las cuales en el funcionariado impera la adicción al secreto y esto hace que "la administración de la diplomacia sólo pueda ser controlada públicamente en un grado muy limitado". Por cierto, en eso consiste su poder'.

Una descripción muy cruda sobre este fenómeno fue hecha por el abogado, historiador y diplomático de carrera Mario Barros Van Buren. Así se desprende de los siguientes extractos de su notable Historia diplomática de Chile (1970)::

"Nuestra diplomacia de los dos siglos pasados transcurrió en 'la esclavitud jurídica' y en un contexto de 'espantosa orfandad de imaginación'. Argentinos conspicuos nos trataban 'como tontos' y en Lima se definía a nuestra Cancillería como 'la gran sorprendida'. En vez de aprovechar a los diplomáticos profesionales meritorios, la autoridad prefería encargar las misiones delicadas al exterior al brillante areópago de abogados, profesores y eruditos que constituían el orgullo del Chile decimonónico"10.

\section{Dicho en Chile.}

Afortunadamente, además de Tomassini y Barros Van Buren, ha existido y existe una élite intelectual chilena que tiene claro lo decisivo de aplicarse a la realidad y lo disfuncional de rendirse ante la jusdiplomacia. Es instructivo rescatar algunas de sus expresiones más representativas.

Carlos Martínez Sotomayor, uno de nuestros cancilleres más sabios, fue el campeón de la negociación diplomática. Sostenía que ésta "no sólo es acertada cuando obtiene pleno éxito en

Weber, Max. Ensayos de sociología contemporánea. Barcelona, Editorial Planeta, 1985, t. I, pp. 31 y 217

10 Barros Van Buren, Mario. Historia diplomática de Chile. Ediciones Ariel, Barcelona, 1970. 
Revista Tribuna Internacional

Volumen $4 \cdot \mathrm{N}^{\text {o }} 8 \cdot 2015 \cdot$ pp. 87-105

ISSN 0719-482X (versión en línea)

la consecución del objetivo perseguido, sino también cuando, considerando las circunstancias adversas que la rodean, logra evitar lo peor para el interés nacional"11.

El embajador, abogado y académico Jorge Heine escribió que "reducir la acción internacional de un país al respeto de las normas jurídicas internacionales es equivalente a decir que el objetivo político clave de un gobierno debe ser respetar la Constitución y las leyes"12.

El abogado, ex embajador y ex Director de la Academia Diplomática de Chile, Eduardo Ortiz Romero, aludiendo a las limitaciones del derecho internacional, escribió que la relación entre naciones e individuos "sigue y se desarrolla 'a pesar' de las normas o en ausencia de ellas"

Jaime Ravinet, abogado y ex Ministro de Defensa Nacional, declaró que "tenemos una falla sistémica e histórica, que es creer que las relaciones exteriores son la argumentación formal del derecho internacional"14.

El historiador Mario Góngora, tras afirmar que en el siglo XX Chile alcanzó límites territoriales que sintió como naturales, agregó que nuestro país "se hace indiferente a problemas de política exterior, delegando su solución en funcionarios o en las Fuerzas Armadas"15.

\section{Ideología legalista}

Por falta de atención a los aspectos político-diplomático-culturales, nuestra reacción ante los conflictos vecinales suele reflejar desubicación. Nos esforzamos por asegurar que "Chile no es un país expansionista" y que "estamos satisfechos con lo que tenemos", ignorando que nuestros vecinos no están satisfechos con lo que perdieron.

En esa línea, nuestro talante oficial se identifica con el estricto respeto al derecho internacional y a los "tratados intangibles". No llegamos a sospechar que esa adhesión, que hoy luce como un fenómeno natural, fue una opción de los países vencedores, en una época en que las victorias bélicas eran fuente de derecho. Es lo que sugirió Hans J. Morgenthau cuando la definió como "ideología legalista", por su funcionalidad para las políticas de mantención de un

11 Martínez Sotomayor, Carlos. Discurso de 23 de agosto de 1984, Santiago, Ediciones de la Academia de Ciencias Sociales, Políticas y Morales, 2000, p. 592.

12 Heine, Jorge. "¿Timidez o pragmatismo? La política exterior de Chile en 1990", Documento de trabajo de Prospel, septiembre 1991, p. 44.

13 Ortiz Romero, Eduardo. El estudio de las relaciones internacionales. Santiago, Fondo de Cultura Económica de Chile, 2000, p. 26.

14 Entrevista en ElMercurio, 18 de octubre de 2015.

15 Entrevistado por Raquel CORREA en El Mercurio, 9 de diciembre de 1984. 
Chile-Bolivia: Un caso de diplomacia secuestrada

José Rodríguez Elizondo

statu quo ${ }^{16}$. Visto así, es impensable, por ejemplo, que la política boliviana valore, como nosotros, la intangibilidad de los tratados.

Lo nuevo es que ese juridicismo histórico hoy se está aplicando en contra de Chile, a manera de "contrasimbolización". Así lo ha observado, entre otros, el politólogo de la Universidad de Utrecht, Gerard van der Ree, para quien "paradójicamente, la identidad legalista de Chile ha brindado a sus dos vecinos (Perú y Bolivia) una estrategia para sus reclamaciones. En vez de infructuosas insistencias en la naturaleza política y bilateral de los conflictos, ambos han optado por seguir una estrategia legalista" ${ }^{\text {17 }}$.

Es lo que debió quedarnos claro en 2002, cuando el Presidente Alejandro Toledo repuso, ante su homólogo chileno Ricardo Lagos, la pretensión marítima peruana formulada en 1986 por Alan García, a través del (hoy) célebre “memorándum Bákula”. Para el Chile oficial fue una sorpresa, pues el general Pinochet había ocultado esa información a sus sucesores de la transición democrática.

Agrego que Toledo replanteó el tema en un marco muchísimo más complejo que el de 1986. Un equipo peruano multidisciplinario, con base en Torre Tagle, aprovechando el larguísimo plazo y administrando la información, terminó construyendo una estrategia sofisticada. Su objetivo político iba, ahora, más allá de la contención de Bolivia y la retorsión contra Chile por las negociaciones ariqueñas de Charaña-, $\tan$ transparentes en el libro El mar peruano y sus limites, de 1977, del pionero almirante Guillermo Faura ${ }^{18}$. Con el paso del tiempo, la diplomacia peruana había llegado a decodificar el silencio de Pinochet como síntoma de incerteza y/o debilidad, lo cual avalaba su pretensión de disputar territorio marítimo a Chile sin el pretexto de Charaña. Ahora era una estrategia de acción.

Conducida por Bákula, esa estrategia se apoyó en la iniciativa permanente, el "poder suave" y la aproximación indirecta, propias del nuevo paradigma diplomático. Esto permitía eludir la confrontación político-diplomática-disuasiva y circunscribía el conflicto al ámbito legal, con dos opciones abiertas: negociación condicionada a la distribución equitativa de las aguas, según normas de la Convención del Mar, o contencioso ante la CIJ, con base en el Pacto de Bogotá. Paralelamente, postulaba la mantención por “cuerdas separadas" del entramado ordinario de relaciones bilaterales y desplegaba una sutil diplomacia regional. Esta tenía, como puntos básicos, la comprensión de Argentina y Brasil, la neutralización de Ecuador y la creación de expectativas sustitutas en Bolivia, fundadas en el efecto-demostración.

16 Morgenthau, Hans J. La lucha por el poder y por la paz. Buenos Aires, Editorial Sudamericana, 1963, p. 127.

17 VAN DER REE, Gerard. "Chile's (inter)national identities: framing the relations with Bolivia and Peru", en Bulletin of Latin American Research, vol. 29, N², 2010.

18 Respecto a la vinculación Arica-Charaña-La Haya sostuve una discusión por años con Juan Miguel Bákula. A la inversa, encontré un notable reconocimiento del fondo ariqueño y trilateral del conflicto en el ex Presidente boliviano Carlos Mesa. Vid. desarrollo de este tema en mis libros De Charaña a La Haya, Santiago, Editorial Planeta Chilena, 2008; e Historia de dos demandas: Perú y Bolivia contra Chile, Santiago, Editorial El Mercurio-Aguilar, 2014. 


\section{Tesis de la innegociabilidad}

En esas circunstancias, el gobierno de Lagos quedó en el peor de los mundos. Tal vez su talante laico le decía que sólo son intangibles los textos que reflejan la palabra divina... y sólo para los creyentes. Sin embargo, la cobertura jurídica de la estrategia peruana le ocultaba su fundamento político real.

A esa altura, el memorándum Bákula era un simple non paper para los pocos funcionarios civiles enterados. La canciller Soledad Alvear no tenía noticias previas del tema. El canciller de Toledo, Allan Wagner, estaba en su origen desde 1986. Por otra parte, no había diplomacia chilena especializada y la realmente existente estaba volcada a la negociación comercial. A mayor abundamiento, los diplomáticos de carrera percibían que no había políticas ni estructuras que les permitieran ejercer su creatividad. El sistema los había mantenido en la reactividad sistemática, incluso después de la dictadura.

Fue así como, en vez de buscar el apoyo de los estrategos -civiles o militares-, los historiadores actualizados y los expertos en política vecinal, el gobierno se redujo a la opinión de los técnicos legales. Estos, muy weberianamente, soslayaron lo expresado en un informe previo de la Asesoría Jurídica de la Cancillería, que advertía la inexistencia de un "tratado específico" de frontera marítima con Perú y emitieron un dictamen conocido sólo por sus efectos. Según éstos, Chile no debía admitir un diferendo en la materia, pues había tratados vigentes ("intangibles") que fijaban la frontera marítima y Perú los venía respetando por casi medio siglo. Paralelamente, esa burocracia comenzó a elaborar una tesis ideológica según la cual los conflictos que afectan la soberanía no son negociables. Un caso de excepcionalismo superlativo, en cuya virtud la idea jurídica, al ser absolutizada, se convertía en un fetiche.

Entendiendo, quizás, que aquello sonaba extramuros como "no podemos discutir porque yo tengo la razón", Lagos se limitó a decir lo que el conflicto no era: "no existe controversia jurídica con Perú". Con ello cerró por dentro la puerta de la negociación e introdujo a Chile, por vía de la negación técnica, al terreno "estrictamente jurídico" que había previsto Bákula. En los años que siguieron -que cubren el primer período de gobierno de Michelle Bachelet-, los expertos de Torre Tagle sólo tendrían que producir las pruebas que justificaran la juridicidad de su pretensión. Con ellas vendría la construcción de un caso jurídico plausible, la resignación confusa del gobierno chileno ${ }^{19}$ y la demanda de 2008 que presentó García, de nuevo en la Presidencia.

19 Vid. sobre este punto, BARros, Jose Miguel. Intervención de 25 de mayo del 2009, en La sociedad chilena en el nuevo siglo, recopilación de conversaciones y diálogos (1991-2012), Santiago, Academia de Ciencias Sociales, Políticas y Morales, 2013, p. 487. 
Chile-Bolivia: Un caso de diplomacia secuestrada

José Rodríguez Elizondo

El general (r) y académico Ernesto Videla, profundo conocedor de la temática vecinal de Chile, manifestó entonces su extrañeza ante "la ausencia de un análisis agudo del panorama vecinal en su conjunto y de la interrelación de lo que ocurre en cada uno de ellos". Terminó con una nota de educado pesimismo: "Temo que nuestra política vecinal se está apartando de ser una política de Estado"20.

Como nota curiosa, antes de asumir su segundo mandato, García había enviado señales a Bachelet de que no deseaba efectivizar la demanda, pues pensaba que Toledo había maltratado gratuitamente la relación con Chile. Y no sólo eso, año y medio después de presentado el instrumento, diría a un diario chileno que incluso había intentado pactar un retroceso: "todo se pudo negociar sobre una mesa de manera diplomática, con una variación del ángulo que matara el tema para siempre" 21 .

No conozco reacciones oficiales sobre tan sorprendente declaración.

\section{El error de origen}

Cuando Chile negoció bilateralmente con Bolivia una salida soberana por Arica, sujeta a la posterior "anuencia" del Perú (1949-1951), cometió un error que le fue reprochado proféticamente por Conrado Ríos Gallardo, negociador del Tratado de 1929 y su protocolo complementario. Dijo, en síntesis, que si entonces no teníamos problemas fronterizos con Perú, los tendríamos en el futuro ${ }^{22}$. Vista esa profecía desde el retrovisor de la historia, puede verificarse que los efectos del error fueron uniformemente progresivos y también comprendieron la relación con Bolivia.

Así, en 1952, la diplomacia peruana se negó a ratificar la fórmula del ex Presidente José Luis Bustamante y Rivero sobre el paralelo geográfico como límite de la frontera marítima con Chile. En 1976, en lugar de aprobar o vetar los acuerdos de Charaña, el gobierno del general Francisco Morales Bermúdez propuso ampliar la presencia peruana en Arica. En 1977 se publicaron las tesis reivindicativas del almirante Faura. En 1986, el Presidente García comunicó que no existía un tratado específico de frontera marítima chileno-peruana. En 2002, el Presidente Toledo advirtió que demandaría a Chile ante la CIJ para definir esa frontera e interfirió en la negociación chileno-boliviana sobre una Zona Económica Especial. En 2008, García -segundo mandato- dispuso presentar esa demanda en La Haya, para que la CIJ fijara la frontera marítima.

20 Videla, Ernesto. Intervención de 25 de mayo del 2009, en La sociedad chilena en el nuevo siglo..., op.cit., p. 496.

21 Entrevista de Cristián Bofill, en La Tercera, 23 de agosto 2009.

22 Este tema fue analizado in extenso en mis libros De Charaña a la Haya e Historia de dos demandas..., ya citados. 
Revista Tribuna Internacional

Volumen $4 \cdot \mathrm{N}^{\text {o }} 8 \cdot 2015 \cdot$ pp. 87-105

ISSN 0719-482X (versión en línea)

Los gobiernos de Bolivia, por su parte, internacionalizaron incrementalmente su aspiración marítima. En esa línea lograron, en 1975, que Chile repusiera su oferta de un corredor soberano por Arica, instalando la percepción de que había un "tema pendiente" de tipo bilateral. Rompieron, reanudaron y volvieron a romper relaciones con Chile, tras vincularlas con la satisfacción de lo pedido. Consiguieron ventajas bilaterales de acceso al mar, en sendas negociaciones con Chile y Perú. Se desentendieron de la diplomacia tradicional para reemplazarla por "la diplomacia del gas", condicionando la venta de sus hidrocarburos a la cesión chilena de una salida soberana al mar y exigiendo que Argentina no "triangulara" hacia Chile sus propias importaciones. Luego, bajo el liderazgo refundacional de Evo Morales, Bolivia lanzó una agresiva "diplomacia de los pueblos" y firmó con Michelle Bachelet la "agenda de los 13 puntos", que consigna expresamente el tema marítimo. Sobre esa base dialogó, presionante, con su homóloga chilena e insultante, con el Presidente Sebastián Piñera. Paralelamente, constitucionalizó "el derecho irrenunciable e imprescriptible sobre el territorio que le dé acceso (a Bolivia) al Océano Pacífico y su espacio marítimo”. También constitucionalizó la obligación correlativa de renegociar o denunciar, unilateralmente, cualquier tratado adverso a esa formulación (léase Tratado de 1904) "en el plazo de dos años desde la selección del nuevo Órgano Ejecutivo”. Cuando llegó el vencimiento de este plazo, Morales entendió que esa obligación se podía cumplir demandando a Chile.

Anótese, como digresión, que esa función instrumental de la demanda no fue contemplada por la CIJ al fallar las excepciones preliminares de Chile. Al sostener que no afectaba al Tratado de 1904, desconoció su vinculación con el plazo constitucional que se autoimpuso Morales para socavar su vigencia.

\section{Salto cualitativo de Bolivia}

En 2013, Morales dio un salto cualitativo en su estrategia, demandando a Chile ante la CIJ. Esta judicialización, inspirada en la demanda peruana y justificada en su nueva Constitución, tiene una importancia política poco advertida. En lo principal, porque da por agotado el procedimiento de negociación bilateral con Chile, con la eventual anuencia a posteriori del Perú, que se intentara en 1949-1951 y en 1975-1976. Además, porque refleja una percepción de gran éxito en la línea internacionalizante. Esto estaría refrendado por la posterior bendición del Papa Francisco, la adhesión expresa de distintos países de la región y la simpatía encubierta de potencias extrarregionales.

En el nuevo marco estratégico, Morales luce convencido de que el solo hecho de llevar a nuestro país ante la CIJ fue una victoria táctica, ratificada con el rechazo del tribunal a las excepciones de incompetencia interpuestas por Chile. Todo ello demuestra -y no sólo a él- 
que la sólida posición jurídica de Chile no fue disuasiva; que la variable internacionalizante boliviana está llegando a la globalización, vía ONU y Vaticano; y que los gobiernos del mundo soportan la idea de que se debilite un tratado de límites, mientras no los afecte a ellos. Apoyándose en el "bilateralismo" del tema, ninguno ha avalado públicamente a Chile en su defensa de los "tratados intangibles".

Por estas y otras consideraciones, la estrategia boliviana hoy debe decodificarse como de aproximación indirecta y no armada (que no es lo mismo que "pacífica") al objetivo, por aplicación creativa de las tesis del autor británico Basil H. Liddell Hart ${ }^{23}$. Puede apostarse, por tanto, que ningún fallo de la CIJ será funcional a la intangibilidad del tratado de límites de 1904 y que un eventual fallo final adverso a Bolivia no detendrá las acciones de Morales.

El líder boliviano, invocando la mera existencia de la litis y la competencia de la CIJ como trofeos globales, seguirá alentando la expansión y profundización del conflicto, mediante el trinomio iniciativa-desplante-sorpresa.

\section{Opción del artículo 53}

La esencial politicidad de la demanda boliviana tiene una fuerte vinculación con la astucia maquiaveliana de Alan García. Este la indujo a través de su embajador en Bolivia, Manuel Rodríguez Cuadros, tras una dura polémica con Evo Morales. Como para éste la demanda peruana tenía por objeto "perjudicar a Bolivia”, Rodríguez Cuadros lo convenció de que, a la inversa, era "la llave para abrir el candado" hacia el mar. De visita post presidencial en Chile, García nos dio un consejo coloquial que reflejaba su íntimo conocimiento de esos entretelones: "no le den bola a la demanda boliviana"24.

Ponderando esa y otras astucias, con base en la información abierta y ante la necesidad de evitar otro escenario lamentable - de nuevo Chile visualizaba un pleito en que sólo podía ganar su contraparte-, yo planteé la posibilidad de una "excepción definitiva de competencia". En lugar de proyectarse desde la litis, con excepciones formateadas por la CIJ, bastaba con abstenerse de comparecer al proceso ahorrándonos, de paso, viajes, contramemoria, dúplica y honorarios de abogados litigantes contratados. Por cierto, era una manera política de afirmar soberanía sin ambages, pero también era la manera jurídica de hacerlo, pues estaba prevista en el artículo 53 del Estatuto de la CIJ. Este dice lo siguiente:

LIDDELL HART, Estrategia..., op.cit., p. 212.

24 Tema desarrollado en mi libro Historia de dos demandas..., op.cit., pp. 141-145. 
Revista Tribuna Internacional

Volumen $4 \cdot \mathrm{N}^{\text {o }} 8 \cdot 2015 \cdot$ pp. 87-105

ISSN 0719-482X (versión en línea)

"1. Cuando una de las partes no comparezca ante la Corte, o se abstenga de defender su caso, la otra parte podrá pedir a la Corte que decida a su favor.

2. Antes de dictar su decisión, la Corte deberá asegurarse no sólo de que tiene competencia conforme a las disposiciones de los artículos 36 y 37, sino también de que la demanda está bien fundada en cuanto a los hechos y al derecho".

Como puede observarse, este texto legitima la posibilidad de que, por cualquier motivo, un Estado demandado decida no defenderse en sede judicial. El reglamento agrega que esto puede hacerse "en ciertas fases de los asuntos o durante todo el asunto". También implica que la Corte debe examinar de oficio su propia competencia, sin necesidad de que previamente se entable una litis formal.

Aplicar esta opción no significaba renunciar a la defensa, en general, sino a la específica defensa ante la CIJ. Nada impedía que, junto con acogerse al artículo 53, Chile adjuntara al tribunal todos los antecedentes, -jurídicos y no jurídicos- por vía informativa, con copia al Secretario General de la ONU, "el más alto funcionario administrativo" del sistema, según la Carta de la organización mundial. En paralelo, nuestro país podía ejercer otros recursos defensivos (políticos, diplomáticos y comunicacionales, por ejemplo), ante cualquier otra instancia, comprendida la propia ONU. En esas circunstancias, la CIJ se tendría que pronunciar de oficio sobre su competencia propia y sobre la juridicidad de la demanda, con el aparato político onusiano sobre aviso y sin necesidad de que se lo pidiera un Chile comprometido con el proceso.

La diferencia con las excepciones preliminares de competencia era significativa pues, sin desacatar a la CIJ, Chile no tendría necesidad de asegurarle a nadie lo que sí pudo asegurarle a todos respecto a la demanda peruana: que el fallo se cumpliría fuere cual fuese. Es decir, que no habría fallo "inaceptable".

Además, la ventaja mayor sería política, comunicacional y diplomática, pues se eliminaba el "punto de prensa" estable que significaba un largo juicio, para un presidente tan movedizo como Evo Morales.

Obviamente, no era una opción sin riesgo. Eso no existe. Pero era un riesgo menor al de una soberanía chilena bajo hipoteca judicial. 


\section{Opción desestimada}

El solo aceptar a tramitación la demanda boliviana, como hizo la CIJ, afectó la solidez del tratado de límites de 1904. Los políticos ilustrados lo entendieron mejor que los otros y los militares mejor que los civiles ${ }^{25}$.

Sin embargo, los abogados y diplomáticos vinculados a la defensa jurídica oficial objetaron, de inmediato, la opción de no entrar al litigio. Arguyeron que invocar el artículo 53 equivalía a quedar sin defensa alguna y a colocarnos "en rebeldía". Otros actores soslayaron los tecnicismos y dijeron que Chile no tenía la envergadura política suficiente para tamaña aventura. Algunos, los más divertidos, dijeron que era una simple locura de este servidor.

Los temas de la indefensión y del riesgo ya se expusieron en el punto anterior. En cuanto a la supuesta rebeldía ante la CIJ, baste señalar que sería una paradoja enorme abrir a los Estados demandados la posibilidad de no comparecer a proceso, para después convertirlos en "Estados rebeldes"... y sin necesidad de declaración formal. Esta objeción es propia de quienes ven el derecho internacional como una extensión analógica del derecho privado doméstico, aunque omitiendo que en éste la rebeldía requiere expresa declaración judicial.

Notablemente, ese afán analógico ya se había evidenciado en episodios anteriores, con los mismos actores nacionales. Fue el talante que mostró en 1976 Hugo Rosende Subiabre, decano designado de la Facultad de Derecho de la Universidad de Chile, analizando la contrapropuesta peruana a los Acuerdos de Charaña. En cuanto asesor de Pinochet y especialista en Derecho Civil, dictaminó que no había problema para ceder una franja ariqueña a Bolivia, pues "el título jurídico en que se fundamenta la cesión pertenece exclusivamente a Chile [...] y el asentimiento peruano es necesario sólo para el perfeccionamiento del traspaso". Para Rosende, ese conflicto internacional era un caso simple de derecho de los contratos ${ }^{26}$.

$\mathrm{Al}$ parecer, no hubo igual celo para investigar opciones distintas a la judicial. Al respecto, anoto dos omisiones "técnicas". La primera, la falta de un informe en derecho sobre el artículo 53 y su jurisprudencia, única manera rigurosa de argumentar tan tajantemente contra su aplicación. Hasta donde yo conozco, los negadores se conformaron con picotear en textos ajenos, incluso a contrapelo de la objetividad de la CIJ. Esta, en folleto distribuido por los centros de información de la ONU, informa que el artículo 53 ha sido invocado en varios casos importantes -cita una decena a modo de ejemplo- y que, eventualmente, ello ha provocado el

25 Vid. León, Pablo; Faundes, Cristián; y Gallardo, Marjorie (editores). La Punta del iceberg. La aspiración marítima boliviana y sus implicancias en la seguridady defensa de Chile. Santiago, Centro de Estudios Estratégicos de la Academia de Guerra, 2015. [Vid. recensión de esta obra en esta misma Revista].

26 Informe de 1 de diciembre de 1976, en folleto Acceso al marpara Bolivia, posición del gobierno de Chile, publicación s/f ni sello editor, distribuido por Sergio Onofre Jarpa, a la sazón embajador de Chile en Colombia. 
desistimiento del Estado demandante ${ }^{27}$. Sobre la base de esa norma, la CIJ también ha llegado a declararse incompetente de oficio, sin excepciones preliminares de por medio ${ }^{28}$. Antonio Remiro Brotóns -abogado español contratado por Bolivia-, reconoció lo señalado en su libro Derecho Internacional Público, al informar que "en la mitad de los procesos seguidos en rebeldía del demandado la Corte se ha declarado competente para conocer del fondo del litigio" 29 . Al margen de la nomenclatura errónea sobre rebeldía, el porcentaje tácito en que la CIJ declara su incompetencia -la otra mitad- es muy digno de consideración.

La segunda omisión radica en el olvido de ese argumento dirimente conocido como "historia fidedigna del establecimiento de la ley". En la especie, ésta nos revela que la razón de ser del artículo 53 radica en el carácter voluntario ab initio que tiene la jurisdicción de la CIJ y en el rechazo a las "cuestiones de naturaleza esencialmente política". Todo ello a partir de la recomendación hecha en 1943 por un comité interaliado de juristas convocado por el Reino Unido $^{30}$.

Consecuente con su historia, la CIJ no está en condiciones de declarar la rebeldía de ningún Estado, ni siquiera de los que se hayan comprometido a asumir su jurisdicción como obligatoria, en el marco de actuaciones políticas que no le conciernen. En esa situación se encuentra el Pacto de Bogotá de 1948, por el cual diversos países de la región se comprometieron a someter sus conflictos a la CIJ, no sin antes condicionar tal sumisión con una buena cantidad de "reservas".

Este es un tema que, por complicarla ontológicamente, la CIJ considera propio de la facultad declarativa de los Estados (artículo 36 de su estatuto). Haciéndolo, oscila entre la simpatía, porque aquello fortalece su estatus, y la inoponibilidad, pues sabe que no puede imponer su jurisdicción a ningún Estado. Consecuentemente, el control de la obligatoriedad que asumieron los firmantes del Pacto de Bogotá sólo corresponde a ellos y así se desprende del artículo L del mismo $^{31}$. Por lo demás, a ese nivel de exasperación conflictual, lo más seguro es que la competencia onusiana ya esté en manos del Consejo de Seguridad, el órgano político del sistema ${ }^{32}$.

27 Vid. NACiOnes Unidas (CIJ). La Corte Internacional de Justicia. La Haya, Corte Internacional de Justicia, 1976, p. 32.

28 Vid. Caso sobre plataforma continental del Mar Egeo (Grecia c. Turquía), iniciado por demanda de 10 de agosto de 1976. El Estado demandado no se presentó y la CIJ analizó su competencia según lo prescribe el artículo 53 del Estatuto de la CIJ. Por fallo de 19 de diciembre de 1978, y por 12 votos contra 2, resolvió que carecía de competencia para conocer de la solicitud presentada por el gobierno griego.

29 Remiro Brotóns, Antonio. Derecho Internacional Público. Curso general. Valencia,Tirant lo Blanch, 2010, p. 654.

30 Vid. NACIONES UnIDAS, La Corte Internacional de Justicia..., op.cit., pp. 15-16

31 El artículo L del Pacto de Bogotá dispone que "si una de las Altas Partes Contratantes dejare de cumplir las obligaciones que le imponga un fallo de la Corte Internacional de Justicia [...], la otra u otras partes interesadas, antes de recurrir al Consejo de Seguridad de las Naciones Unidas, promoverá una Reunión de Consulta de Ministros de Relaciones Exteriores a fin de que acuerde las medidas que convenga tomar para que se ejecute la decisión judicial o arbitral". Agradezco este aporte a mi experto amigo Luis Fernando Morales.

32 Una aproximación a este tema en mi artículo "La ONU entre la Corte y el Consejo", en Realidad y Perspectivas, $\mathrm{N}^{\circ}$ 16, diciembre de 2012. 
Chile-Bolivia: Un caso de diplomacia secuestrada

José Rodríguez Elizondo

Por todo lo señalado, me permito suponer que la "rebeldía" y la "indefensión" de Chile son fantasmones funcionales al interés de los abogados que litigan ante la CIJ. Obviamente, a ellos no les conviene recomendar ni aplicar un texto que permite a los Estados clientes prescindir de sus servicios.

\section{2. ¿Demasiado poco, demasiado tarde?}

Tras el fallo de 24 de septiembre de 2015, en que la CIJ rechazó nuestras excepciones preliminares de competencia, por 14 votos contra dos, el canciller Heraldo Muñoz anunció que Chile pasaba a una nueva etapa, con mayor proyección política, diplomática y comunicacional. Para ese efecto, anunció el refuerzo del equipo chileno con tres personalidades de mérito indiscutido: el historiador Joaquín Fermandois, el periodista Ascanio Cavallo y el politólogo Gabriel Gaspar, a la sazón Subsecretario del Ministerio de Defensa y antes embajador en Cuba y Colombia. Este pronto dejaría en claro que el juridicismo era "un error del pasado" y que "estamos hablando de armar una estrategia nacional",33.

Aunque en diferido, fue una señal de que por fin se había captado la debilidad de una defensa exclusivamente técnica. A esa altura ya era visible la asimetría entre el equipo chileno y el de Bolivia, encabezado por representantes de la más alta institucionalidad política del Estado (dos ex presidentes de la República). En el pleito anterior había sucedido algo similar, pues el equipo peruano estuvo liderado por la más alta institucionalidad político-diplomática de Torre Tagle (dos ex cancilleres).

Sin embargo, la buena señal no impidió que se alzaran voces importantes, con opciones más audaces que la mía. Planteaban el equivalente al "demasiado poco, demasiado tarde" y hasta llamaban a declarar inaceptable cualquier eventual fallo que nos obligue a negociar soberanía. El abogado y ex ministro de Defensa Jaime Ravinet fue especialmente categórico: "Lo cuerdo es decir ahora que la Corte no tiene jurisdicción sobre este tema, que no aceptamos su fallo, que el fallo es inoponible"34. Similar talante exhibió Fabio Vio, uno de nuestros embajadores más experimentados, para quien por primera vez en la historia no existía entre los agentes chilenos a cargo de un conflicto un diplomático de carrera que aportara su conocimiento. Agregó que era necesario retirarse del proceso y "denunciar, urgentemente, el Pacto de Bogotá" "35. Antes habían opinado en sentido similar cuatro destacados embajadores de carrera, lamentando nuestra "falta de profesionalismo" y el que no se tocara el tema del pleito en la

33 Entrevista en La Tercera, 1 de noviembre del 2015.

34 Entrevista en ElMercurio, 18 de octubre de 2010.

35 Entrevista en ElMercurio, 1 de noviembre de 2015. 
Asamblea de la ONU. A su juicio, fue una "insólita forma de hacer política exterior cuando está en juego la defensa de nuestra soberanía"36.

Además, con el mérito de los hechos judiciales adversos, la opinión pública, ilustrada o no, comienza a reconocer lo que debió ser obvio ab initio: que el objetivo estratégico de Evo Morales no era imponer una tesis jurídica, sino acumular puntos políticos, diplomáticos y comunicacionales para aislarnos. Una acción que -ya lo hemos visto- está en la base de las tesis de la aproximación indirecta y del "poder suave" y en las antípodas de nuestra fe en la santidad de los tratados.

\section{Conclusiones contingentes}

El reforzamiento del equipo de Chile y el talante realista de los nuevos integrantes permiten mirar el futuro con más esperanza. Con todo, tras más de siete años con una diplomacia metafóricamente secuestrada por jueces y abogados litigantes extranjeros, se requerirían gestos mayores. Por ejemplo, un viraje presidencial orientado a recuperar los espacios políticos perdidos, el reinicio de los trabajos diplomáticos abandonados, la deconstrucción histórica del bilateralismo ficticio, la revisión de los errores cometidos -en vez de su ocultamiento- y el estudio de técnicas y estrategias de negociación que den cuenta de nuestras posibilidades y limitaciones.

Como son todas circunstancias de alta complejidad, ligadas a escenarios hipotéticos, a debates reservados y a un nuevo talante de los líderes políticos, lo más prudente es conformarnos con las siguientes conclusiones provisionales:

- La CIJ ya decidió sobre la soberanía de espacios marítimos que Chile consideraba propios, en el caso con Perú, y hoy se considera competente para incidir sobre la capacidad chilena de negociar en materias estratégicas con Bolivia.

- Así como en el caso con Perú enfatizamos la conformidad de la CIJ con "los principios jurídicos de la defensa chilena", soslayando la pérdida real de espacio marítimo, en el caso con Bolivia el rechazo de las excepciones preliminares se ha valorado por un sesgo colateral: la "acotación" de la pretensión boliviana de que la CIJ predetermine el resultado de la negociación con Chile.

- Como en Chile no funciona a cabalidad la relación dinámica Derecho-Diplomacia-Defensa, nuestros expertos oficiales han postulado la "innegociabilidad" de los conflictos que afecten

36 Embajadores Juan Salazar, Carlos Klammer, Felipe Du Monceau y Benjamín Concha, en carta a El Mercurio de 15 de octubre de 2015. Sugiero leer, además, carta a diario La Tercera de 16 de octubre de 2015, del ex Comandante en Jefe de la Armada, almirante (r) Miguel Angel Vergara Villalobos. 
nuestra soberanía, hipostasiando el concepto de "tratados intangibles". Otros, más místicos, hablan de "la santidad de los tratados". Son idealizaciones que facilitaron la intervención de la CIJ.

- Los tratados de límites deben ser objeto de mantención preferente, mediante políticas de Estado que enriquezcan la relación, creando intereses compartidos y desarrollando técnicas de negociación para prevenir los conflictos. Está demostrado que el supuesto carisma de su intangibilidad no basta para mantener el statu quo.

- La historia de los tratados de límites enseña que suelen derivar de "hechos de dominación", los cuales antes tenían legitimidad global. También enseña que no existe el tratado blindado o a prueba de interpretaciones disidentes, capaces de generar hechos nuevos. Así, en el caso peruano se alegó la inexistencia de un tratado específico de frontera marítima y, en el boliviano, se constitucionalizó la decisión de desconocer el Tratado de 1904.

- Como resultado de los puntos anteriores, la Cancillería chilena se ha concentrado, por más de siete años, en defender al país ante la CIJ. Con ello se ha visto clavada en la situación del litigante que no puede ganar y que sólo aspira a mantener el statu quo, ante jueces que tienen objetivos propios y diferenciados.

- Cerrando el círculo problemático, también hay falencias en el ámbito de nuestra profesionalidad jurídica. El Consejo Chileno de Relaciones Internacionales, a través de su Presidente Hernán Felipe Errázuriz -abogado y ex canciller-, ha manifestado que "Chile debería tener juristas con más presencia en los foros, academias y cortes internacionales y menos improvisación en la organización de la defensa de sus intereses en los tribunales extranjeros". En el mismo sentido, el académico internacionalista Carlos Dettlef ha recordado lo obvio: "el derecho internacional es totalmente distinto al derecho interno",37.

\section{La fórmula de don Gabriel}

En definitiva, no tuvimos con Perú ni con Bolivia, lo que hay que tener, máxime después de un conflicto tan grave como el de 1879: una Cancillería inserta en el nuevo paradigma, con una diplomacia profesionalizada, idónea para generar iniciativas que faciliten mutar la paz en amistad, una doctrina para prever y enfrentar nuevos conflictos mediante la "triple D" y una estructura que jerarquice la función del servicio exterior por sobre la de los servicios técnicos de apoyo.

Las explicaciones de tales carencias son diversas y exceden la contraposición simplista entre los funcionarios "de la carrera" y los funcionarios "políticos" ingresados por "cuoteo" o como

37 Vid. Consejo Chileno de Relaciones Internacionales. Institucionalidad para la defensa de los intereses del Estado de Chile ante los tribunales internacionales. Diagnóstico y propuestas. Santiago, 2013, pp. 6 y 39. 
Revista Tribuna Internacional

Volumen $4 \cdot \mathrm{N}^{\text {o }} 8 \cdot 2015 \cdot$ pp. 87-105

ISSN 0719-482X (versión en línea)

"ventaneros". Según este reduccionismo con jerga, ahí estaría la clave de la falta de profesionalidad de nuestra diplomacia. Por cierto, eso es soslayar investigaciones como la de Mario Barros Van Buren, identificar el corporativismo weberiano con la modernización y cerrar los ojos ante la responsabilidad basal del sistema político.

Es que, en cuanto institución permanente del Estado, ejecutora de la política exterior y bajo un régimen de presidencialismo excluyente, la explicación del retraso de nuestra Cancillería excede el estatuto de sus funcionarios y autoridades. En lo fundamental, se explica por la resignación o por la débil comprensión que tienen los jefes de Estado y la clase política respecto a la situación internacional de Chile, con especial mención de sus constantes y variables geopolíticas. Dicho en fórmula: no tienen conciencia cabal de que, en el mundo actual, las amenazas estratégicas vienen más desde las cancillerías que desde los ejércitos.

De ahí que los actores políticos sólo por excepción profundicen en los temas y problemas de nuestra política exterior y poco los entusiasme la modernización de la Cancillería. Más bien se limitan a contrastar los conflictos con las leyes nacionales, se tranquilizan porque los cancilleres figuran entre los ministros con mejor rating en las encuestas, aseguran que somos un país muy serio y creen en la eficacia de los apoyos ecuménicos y fotografías ex post, para acciones presidenciales de coyuntura. En eso consiste parte importante de lo que llaman "política exterior de Estado".

Visto que esa ficción política ha aumentado su recurrencia desde el conflicto marítimo con Perú, quizás lo mejor sea ceder la última palabra a Gabriel Valdés Subercaseaux, uno de los más grandes cancilleres de nuestra historia. Desde su última misión en Roma y a pocas semanas de presentada la demanda peruana, él se mostraba preocupado por el estado de nuestra política exterior. Percibía muy bien cuanto incidía la condición disminuida de la Cancillería en el deterioro de la situación vecinal. Decidió insistir, por tanto, en un viejo tema: Chile, abierto al mundo, necesitaba una organización para el siglo XXI. Pero, como sabía que una reforma estructural "no era tema" prioritario para ninguna fuerza política, hizo la siguiente declaración a una periodista:

"Una reforma de este tipo no se puede hacer desde adentro de la Cancillería; hay que hacerla desde fuera, quizás con la asesoría de grandes países, como Gran Bretaña u otros. Hay que buscar una fórmula para que Chile, que es pequeño y no es rico, tenga un funcionamiento externo más adherido a lo que está pasando, que utilice mejor los talentos, que sea una carrera donde lo profesional se pueda perfeccionar con el tiempo, que no sea un pagador de recursos para algunos políticos"38.

Así nos interpeló don Gabriel. Y está claro que no basta con decir amén. La magnitud del desafío no es excusa para perseverar en el error.

38 Entrevistado por Patricia MAYORgA, en El Mercurio, 9 de marzo de 2008. 